\title{
PENERAPAN SISTEM MANAJEMEN KESEHATAN DAN KESELEMATAN KERJA PADA PTPN VII PADANG PELAWI SUKARAJA SELUMA
}

\author{
Mualim, Sri Mulyati, Yusmidiarti \\ Politeknik Kesehatan Kementerian Kesehatan Bengkulu, Jurusan Kesehatan Lingkungan, \\ Jalan Indragiri Nomor 3 Padang Harapan Bengkulu \\ keslingbkl@yahoo.com
}

\begin{abstract}
The latest regulation in Indonesia on Work Safety and Health Management System (SMK3) is Indonesian Republic Goverment Regulation No. 50 of 2012, explained that the current trade globalization impact very tight competition in all aspects, especially for personnel work, one of which requires protection of work safety and health management system. SMK3 implementation under Regulation No. 50 of 2012 had not been evaluated. This study aimed to implement of safety and health management systems work by Indonesian Republic Goverment Regulation No. 50 of 2012 in PTPN VII Sukaraja Seluma district. This research was a qualitative research with observational approach using documentary study of the application of SMK3 through primary and secondary data. The sample in this study was derived from the three directors and the workforce amounted to 30 workers. The instruments those used in this study were guidelines depth interview and questionnaire. Data analyzed by triangulation. PTPN VII Padang Pelawi Sukaraja has conducted an initial review to identify potential hazards such as giving understanding to cope with all workers on the potential dangers that may occur whether caused by physical, chemical, ergonomic, radiation, biological and psychological that may injure and hurt at work, the use of APD in accordance with the following procedures assessment and risk control by technical or engineering controls.
\end{abstract}

Keyword : SMK3 PP No 50 Tahun 2012, PTPN VII Padang Pelawi Sukaraja Seluma

\begin{abstract}
Abstrak : Regulasi terbaru di Indonesia tentang Sistem Manajemen Keselamatan dan Kesehatan Kerja (SMK3) yaitu PP RI Nomor 50 Tahun 2012, dijelaskan bahwa globalisasi perdagangan saat ini memberikan dampak persaingan sangat ketat dalam segala aspek khususnya ketenagaan kerjaan yang salah satunya mempersyaratkan adanya perlindungan atas keselamatan dan kesehatan kerja. Pelaksanaan SMK3 berdasarkan PP RI Nomor 50 Tahun 2012 belum dievaluasi. Tujuan penelitian adalah untuk mengetahui penerapan sistem manajemen keselamatan dan kesehatan kerja berdasarkan PP RI Nomor 50 Tahun 2012 di PTPN VII Sukaraja Kabupaten Seluma. Penelitian ini merupakan penelitian kualitatif dengan pendekatan observasional menggunakan studi dokumentasi terhadap penerapan SMK3 melalui data primer dan sekunder. Sampel dalam penelitian ini adalah tiga orang direksi dan tenaga kerja yang berjumlah 30 pekerja. Instrumen yang digunakan dalam penelitian ini adalah pedoman wawancara mendalam dan kuesioner. Analisis data dengan cara Triangulasi. Peninjauan dan peningkatan kinerja SMK3 PTPN VII Padang Pelawi Sukaraja telah melakukan tinjauan awal seperti mengidentifikasi potensi bahaya mengatasinya dengan memberi pemahaman kepada semua tenaga kerja mengenai potensi bahaya yang dapat terjadi baik yang disebabkan oleh fisik, kimia, ergonomik, radiasi, biologi dan psikologi yang mungkin dapat menciderai dan melukai pada saat bekerja, penggunaan APD sesuai dengan prosedur yang ada berikutnya penilaian dan pengendalian risiko dengan cara pengendalian teknis atau rekayasa.
\end{abstract}

Kata Kunci : SMK3 PP No 50 Tahun 2012, PTPN VII Padang Pelawi Sukaraja Seluma

Penerapan Keselamatan dan Kesehatan Kerja melalui Sistem Manajemen Kesehatan dan Keselamatan Kerja (SMK3) telah berkembang diberbagai negara baik melalui pedoman maupun standar. Untuk meningkatkan efektifitas perlindungan keselamatan dan kesehatan kerja, tidak terlepas dari upaya pelaksanaan keselamatan dan kesehatan kerja yang terencana, terukur, terstruktur dan terintegrasi melalui SMK3 guna menjamin terciptanya 
suatu sistem keselamatan dan kesehatan kerja di tempat kerja dengan melibatkan unsur manajemen, pekerja/buruh, dan atau serikat pekerja/serikat buruh dalam rangka mencegah dan mengurangi kecelakaan kerja dan penyakit akibat kerja serta terciptanya tempat kerja yang nyaman, efisien dan produktif.

Didukung pula dengan adanya regulasi terbaru tentang Sistem Manajemen Keselamatan dan Kesehatan Kerja (SMK3) yaitu PP No. 50 Tahun 2012, dijelaskan bahwa globalisasi perdagangan saat ini memberikan dampak persaingan sangat ketat dalam segala aspek khususnya ketenagaan kerjaan yang salah satunya mempersyaratkan adanya perlindungan atas keselamatan dan kesehatan kerja. Penerapannya wajib melaksanakan penetapan kebijakan $\mathrm{K} 3$, perencanaan $\mathrm{K} 3$, pelaksanaan rencana $\mathrm{K} 3$, pemantauan dan evaluasi kinerja K3 serta peninjauan dan peningkatan kinerja SMK3.

PT Perkebunan Nusantara (PTPN) VII Unit Padang Pelawi Kabupaten Seluma Bengkulu merupakan perusahaan BUMN yang bergerak dalam sub sector komoditas karet yang lokasinya berada dekat jalan raya Bengkulu-Manna Km 26,5 di desa Padang Pelawi, kecamatan Sukaraja, Kabupaten Seluma Bengkulu dengan luas wlayah sebesar 5.804 Ha.

Perusahaan belum melakukan evaluasi Sistem Manajemen Keselamatan dan Kesehatan Kerja. Tujuan Penelitian untuk mengetahui penerapan sistem manajemen keselamatan dan kesehatan kerja berdasarkan PP RI No 50 Tahun 2012 di PTPN VII Sukaraja Kabupaten Seluma. Penerapan SMK3 berdasarkan PP Nomor 50 Tahun 2012 pasal 5 adalah: pertama penetapan Kebijakan SMK3 meliputi Penyusunan kebijakan K3, Penetapan kebijakan K3, Untuk melaksanakan ketentuan penetapan kebijakan, pengusaha, setiap tingkat pimpinan dalam perusahaan harus menunjukkan komitmen terhadap K3 sehingga SMK3 berhasil diterapkan dan dikembangkan. Setiap peker$\mathrm{ja} /$ buruh dan orang lain yang berada di tempat kerja harus berperan serta dalam menjaga dan mengendalikan pelaksanaan K3. Kedua perencanaan K3 meliputi pengusaha menyusun rencana $\mathrm{K} 3$, rencana $\mathrm{K} 3$ yang disusun oleh perusahaan paling sedikit memuat: tujuan dan sasaran, skala prioritas, upaya pengendalian bahaya, penetapan sumber daya, jangka waktu pelaksanaan, indikator pencapaian, sistem pertanggung jawaban. Ketiga Pelaksanaan Rencana K3 meliputi: prosedur pengadan sumber daya manusia, pengadaan sumber daya manusia sesuai kebutuhan dan memiliki kompetensi kerja serta kewenangan di bidang K3, konsultasi, motivasi dan kesadaran. Keempat pemantauan \& evaluasi kinerja K3, pemeriksaan, pengujian dan pengukuran, audit internal SMK3. Kelima peninjauan dan peningkatan kinerja SMK3 meliputi melakukan tinjauan awal K3, serta memperhatikan peningkatan kinerja manajemen $\mathrm{K} 3$.

\section{BAHAN DAN CARA KERJA}

Penelitian ini merupakan penelitian kualitatif dengan pendekatan observasional dengan menggunakan studi dokumentasi terhadap penerapan SMK3 melalui data primer dan sekunder. Populasi dalam penelitian ini adalah semua manajer personalia dan tenaga kerja dibagian proses, sampel dalam penelitian ini berjumlah 30 pekerja. Teknik pengambilan sampel purposife sampel. Adapun instrumen yang digunakan dalam penelitian ini adalah: pedoman wawancara mendalam, kuesioner dan format cek dokumen. Peneliti-an ini menggunakan triangulasi sumber dan metode (Moelong, 2002).

\section{HASIL}

Berdasarkan hasil kuesioner tenaga kerja yang bekerja yang memerlukan K3 yaitu: bongkar, operatoralat berat, mekanik, teknik, pengolahan, produksi dan analis yang mempunyai risiko kecelakaan kerja dan penyakit akibat kerja sebanyak $62 \%$. Umur tenaga kerja yang terbanyak di PTPN VII Padang Pelawi Sukaraja berumur 36 - 51 tahun (62\%). Pendidikan tenaga kerja yang terbanyak di PTPN VII Padang Pelawi Sukaraja menengah (87\%). Lama kerja tenaga kerja yang terbanyak di PTPN VII Padang Pelawi Sukaraja sudah lama (79\%). 
Berdasarkan hasil wawancara dan kuesioner: penetapan kebijakan K3, untuk melak-sanakan ketentuan penetapan kebijakan K3, pengusaha, setiap pimpinan dalam perusahaan harus menunjukkan komitmen terhadap K3 sehingga SMK3 berhasil diterapkan dan dikembangkan. Setiap pekerja/buruh dan orang lain yang berada di tempat kerja harus berperan serta dalam menjaga dan mengendalikan pelaksanaan K3.

Tabel 1. SMK 3 Berdasarkan Penetapan Kebijakan

\begin{tabular}{|c|c|c|}
\hline Kegiatan & Direksi & Tenaga Kerja \\
\hline Penyusunan & $\begin{array}{l}\text { Penyusunan } \\
\text { kebijakan dilaku } \\
\text { kan direksi di } \\
\text { kantor pusat di } \\
\text { Lampung }\end{array}$ & $\begin{array}{l}\text { Ada Hasil penyusu- } \\
\text { nan kebijakan }\end{array}$ \\
\hline Pengesahan & $\begin{array}{l}\text { Kebijakan di } \\
\text { syahkan pihak } \\
\text { manajer }\end{array}$ & $\begin{array}{l}\text { Pengesahan dari pihak } \\
\text { manajer }\end{array}$ \\
\hline $\begin{array}{l}\text { Sosialisasi } \\
\text { Kebijakan }\end{array}$ & $\begin{array}{l}\text { Kebijakan yang } \\
\text { baru disosialisa }\end{array}$ & $\begin{array}{l}\text { Ada sosialisasikan } \\
\text { kepada semua tenaga }\end{array}$ \\
\hline & $\begin{array}{l}\text { sikan kepada } \\
\text { semua tenaga } \\
\text { kerja baik lisan } \\
\text { maupun tertulis }\end{array}$ & $\begin{array}{l}\text { kerja baik lisan, tertu- } \\
\text { lis }\end{array}$ \\
\hline $\begin{array}{l}\text { Menempatkan } \\
\text { personil pe- } \\
\text { nanggung } \\
\text { jawab K3 }\end{array}$ & $\begin{array}{l}\text { Perusahaan } \\
\text { menempat } \\
\text { kan seorang } \\
\text { penanggung } \\
\text { jawab K3 }\end{array}$ & Ada pada setiap \\
\hline $\begin{array}{l}\text { Melakukan } \\
\text { Penilaian ki } \\
\text { nerja }\end{array}$ & $\begin{array}{l}\text { Perusahaan } \\
\text { melakukan } \\
\text { penilaian kinerja } \\
\text { melalui absensi, } \\
\text { SKP }\end{array}$ & $\begin{array}{l}\text { Sudah ada seorang } \\
\text { yang ditugaskan pe- } \\
\text { rusahaan sebagai } \\
\text { penangung jawab K3. } \\
\text { Ada absensi, ada SKP }\end{array}$ \\
\hline
\end{tabular}

"Kami sudah menjalankan program K3 sejak berdirinya perusahaan ini dengan system yang berubah secara dinamis mengikuti regulasi yang ada, adapun system manajemen $\mathrm{K} 3$ di PTPN VII sepenuhnya dikoordinir langsung oleh pak D selaku penanggung jawab K3. Kami melakukan upaya meminimalisir kecelakaan kerja (Informan 1).

"Perusahaan ini tentunya memiliki tinjauan awal dalam K3 yaitu dalam memantau keperluan apa saja yang diperlukan dalam memenuhi persyaratan K3 sudah memfasilitasi karyawan dengan APD dan gambar-gambar mengenai prosedur"(informan 1).

"Untuk penyediaan anggaran disini kami mengadakan anggaran untuk penyediaan APD, adapun APD yang sediakan seperti safety shoes, helm, sarung tangan dan fasilitas-fasilitas lainnya tentang K3 (infor-man 1).

Hasil wawancara di atas diperkuat dengan jawaban tenaga kerja bahwa perusahaan sudah menunjuk personil yang khusus sebagai penanggung jawab K3. Setiap kebijakan baru selalu disebarluaskan kepada tenaga kerja baik secara lisan juga tertulis.

Tabel 2. SMK 3 Berdasarkan Perencanaan K3

\begin{tabular}{lll}
\hline Perencanaan K3 & \multicolumn{1}{c}{ Direksi } & Tenaga Kerja \\
\hline Penyusunan & Penyusunan rencana & Penyusunan \\
rencana : & yang dibuat PTPN & rencana K3 \\
Penelaahan awal & VII sudah dibuat & dibuat direksi, \\
Identififikasi po- & melalui penelaahan & penangung \\
tensi bahaya & awal,identifikasi & jawab K3 yang \\
Peraturan & potensi bahaya, ada & melaksanakan \\
Sumber daya & $\begin{array}{l}\text { peraturan,sumber } \\
\text { daya ditentukan }\end{array}$ & \\
& sesuai kebutuhan & \\
& \multicolumn{3}{c}{ Isi Rencana melipu- } & \\
Isi Rencana & ti: tujuan, sasaran, & Persyaratan \\
Tujuan dan sasa- & skala prioritas, & dalam isi \\
ran & upaya pengendalian, & rencana ter- \\
Skala prioritas & penetapan sumber & muat dalam \\
Upaya pengen- & ada jangka waktu, & rencana K3 \\
dalian & indikator pencapaian & perusahaan \\
Penetapan sumber & dan sistem per- & PTPN VII \\
daya & tanggungjawaban & \\
Jangka waktu & & \\
pelaksanaan & & \\
Indikator pen- & & \\
capaian & & \\
Sistem Per- & & \\
tanggung jawaban & &
\end{tabular}

Hasil yang ditungkan dalam tabel 2 memberi gambaran bahwa system manajemen $\mathrm{K} 3$ melalui rencana K3 semua persyaratan dalam penetapan tersebut sudah dilaksanakan seperti hasil wawancara di bawah ini. Berdasarkan hasil wawancara diketahui bahwa perusahaan sudah memiliki perencanaan secara tertulis "Semua hal yang berkaitan dengan K3 diperusahaan ini dikoordinasikan dengan pihak pusat dalam hal ini kantor pusat kami di Lampung. Semua kebutuhan K3 sudah termasuk dalam rencana anggaran perusahaan" (informan 1).

Hasil wawancara di atas diperkuat dengan jawaban tenaga kerja bahwa perusahaan sudah menganggarkan untuk APD. "Perusahaan belum memiliki perencanaan-perencanaan lebih dalam mengenai K3" (informan 2). Hasil wawancara tersebut diperkuat dengan jawaban tenaga kerja bahwa perusahaan sudah menun- 
juk personil yang khusus sebagai penanggung jawab K3. sawit.

"Danamnatan cava di nrodulcai arralnva beber- melalui pelaksanaan rencana K3 semua persyaratan dalam penetapan tersebut sudah dilaksanakan seperti hasil wawancara di bawah ini. "Penempatan personal sudah sesuai dengan kompetensi tenaga kerja di bidangnya masingmasing, seperti personal yang ditunjuk sebagai koordinator K3 sudah mengikuti pelatihan K3 baik dalam hal penggunaan APD maupun sistem manajemen K3" (Informan 1). "Tenaga kerja disini ditempatkan pada posisi berdasarkan pendidikan terakhir mereka masingmasing, sehingga kami dapat menempatkan mereka berdasarkan kompetensi mereka, secara khusus dalam bidang produksi saudara tahu tidak ada pendidikan khusus terhadap spesialisasi penguasaan mesin, sehingga setiap tenaga kerja baru perlu penyesuaian dalam bidang itu"(informan 2).

Tabel 3. SMK 3 Berdasarkan Pelaksanaan Rencana K3

\begin{tabular}{|c|c|c|}
\hline Kegiatan & Direksi & Tenaga Kerja \\
\hline Pelaksanaan & Pelaksanaan & Ada tenaga \\
\hline Rencana K3 yaitu & rencana $\mathrm{K} 3 \mathrm{di}$ & kerja yang \\
\hline menye- & PTPN VII melalui & diberi tanggung \\
\hline diakan sumber & prosedur dilakukan & jawab untuk \\
\hline daya manusia, & konsultasi, motiva- & menangani $\mathrm{K} 3$ \\
\hline $\begin{array}{l}\text { prosedur penga- } \\
\text { daan. }\end{array}$ & $\begin{array}{ll}\text { si dan } & \text { ada } \\
\text { tanggung } & \text { jawab }\end{array}$ & di perusahaan \\
\hline $\begin{array}{l}\text { Konsultasi, moti- } \\
\text { vasi } \\
\text { kesadaran. }\end{array}$ & $\begin{array}{l}\text { dan tanggung } \\
\text { gugat, pelatihan } \\
\text { bagi tenaga kerja }\end{array}$ & \\
\hline Tanggung jawab & secara berjenjang & \\
\hline \& tanggung gugat. & & \\
\hline Pelatihan dan & Sarana dan prasa- & Perusahaan \\
\hline kompetensi kerja & rana yang dibutuh- & menyediakan \\
\hline Menyediakan & kan dalam sistem & APD yang \\
\hline sarana \& prasara- & manajemen $\mathrm{K} 3$ & dilengkapi \\
\hline na. & diprioritaskan & dengan \\
\hline Apa yang dise- & untuk kebutuhan & prosedur \\
\hline diakan. & K3 seperti APD, & pemakaian, \\
\hline $\begin{array}{l}\text { Tindakan pengen- } \\
\text { dalian. }\end{array}$ & $\begin{array}{l}\text { sebagai tindakan } \\
\text { pengendalian yang }\end{array}$ & $\begin{array}{l}\text { mesin yang } \\
\text { digunakan }\end{array}$ \\
\hline Perancangan dan & dilengkapi dengan & tenaga kerja, \\
\hline rekayasa. & prosedur, penyera- & masih ada yang \\
\hline $\begin{array}{l}\text { Prosedur dan } \\
\text { instruksi kerja. }\end{array}$ & sian. & $\begin{array}{l}\text { belum serasi } \\
\text { dengan tinggi }\end{array}$ \\
\hline Penyerasian & & tenaga kerja \\
\hline pelaksanaan & & \\
\hline pekerjaan. & & \\
\hline \multicolumn{3}{|l|}{$\begin{array}{l}\text { Pembelian barang } \\
\text { dan jasa. }\end{array}$} \\
\hline & Produk akhir beru- & \\
\hline Produk akhir & pa olahan baik & \\
\hline & karet maupun & \\
\hline
\end{tabular}

beberapa Diploma bagian mesin dan semuanya memulainya sambil belajar di sini dan lama kelamaan kami sudah bisa" (informan 5).

Hasil wawancara tersebut diperkuat dengan jawaban tenaga kerja bahwa pendidikan menengah dan sebagian besar tenaga kerja ini bekerja di bagian yang langsung berhubungan dengan faktor risiko kecelakaan akibat kerja dan penyakit akibat kerja serta penyakit yang ada hubungannya dengan pekerjaan.

Setiap informan yang telah diwawancarai mengaku memahami dan mematuhi peraturan dan kebijakan K3 yang telah ditetapkan oleh perusahaan. Pada kenyataannya berdasarkan hasil observasi disertai penelusuran dokumentasi langsung di lapangan ditemukan masih ada tenaga kerja yang tidak menggunakan APD pada saat bertugas. Di pihak lain peraturan sudah ada namun pelaksanaannya belum maksimal (khususnya adanya sangsi bagi tenaga kerja yang tidak disiplin). "Semua aturan mengenai K3 menyangkut keselamatan tenaga kerja perusahaan yang tentunya juga berdampak positif bagi kami pihak penanggung jawab perusahaan. Kami selalu berusaha melakukan yang terbaik bagi perusahaan dan selalu kami buktikan dengan tidak hanya memahaminya juga harus mematuhinya" (informan 3). Seluruh tenaga kerja di perusahaan memahami juga mematuhi peraturan K3 yang ada" (informan 2). "Sebagai petugas dibagian produksi,saya tentunya benar-benar mematuhi peraturan dan kebijakan perusahaan mengenai K3,karena jika saya tidak mematuhi sama saja merugikan diri saya sendiri" (informan 5). Hasil ini diperkuat dengan pendidikan terbanyak menengah.

Hasil yang dituang dalam tabel 4 memberi gambaran bahwa sistem manajemen K3 melalui pemantauan dan evaluasi K3. Semua persyaratan dalam penetapan tersebut sudah dilaksanakan seperti berikut ini.

"K3 adalah sarana penting dalam perusahaan, sekalipun saya tidak bertugas di bagian produksi, namun saya menilai setiap tenaga 
pada semua bagian khususnya yang berhubungan dengan proses produksi banvak tenaga kerja bijak

Setelah melakukan wawancara peneliti juga melakukan observasi dilapangan terlebih khusus melakukan pengamatan terhadap tenaga kerja yang ditempatkan pada mesin produksi, dimana setiap tenaga kerja mengenakan alat pelindung diri seperti safety shoes,sarung tangan dan masker sesuai dengan prosedur K3 di perusahaan,namun mengenai penggunaan helm dan penggunaan ear muff atau ear plug khususnya tenaga kerja yang terpapar dengan kebisingan seperti tenaga kerja yang bertugas di dalam ruang produksi, terlebih yang paling dekat dengan mesin, ditemukan tidak menggunakan, tenaga kerja beralasan tidak nyaman bila mereka menggunakannya.

Tabel 4. SMK 3 Berdasarkan Pemantauan dan evaluasi

\begin{tabular}{|c|c|c|}
\hline Kegiatan & Direksi & Tenaga kerja \\
\hline $\begin{array}{l}\text { Pemantauan dan } \\
\text { Evaluasi } \\
\text { Pemantauan }\end{array}$ & $\begin{array}{l}\text { Pemantauan di } \\
\text { PTPN VII dil- } \\
\text { aksanakan secara } \\
\text { lisan dan tertulis } \\
\text { Pelaksana peman- } \\
\text { tauan ditunjuk su- } \\
\text { pervisor pada setiap } \\
\text { bagian. }\end{array}$ & $\begin{array}{l}\text { Pemantauan } \\
\text { oleh supervisor } \\
\text { dan evaluasi } \\
\text { yang dilakukan } \\
\text { ada saling men- } \\
\text { gisi antara tena- } \\
\text { ga kerja dengan } \\
\text { supervisor. }\end{array}$ \\
\hline Evaluasi & $\begin{array}{lr}\text { Evaluasi } & \text { dil- } \\
\text { aksanakan } & \text { lisan } \\
\text { setiap ada permasa- } \\
\text { lahan dan setiap } \\
\text { bulan }\end{array}$ & \\
\hline
\end{tabular}

Berdasarkan hasil wawancara diketahui perusahaan sudah memilki prosedur pelaporan, mekanisme pelaporan yang disusun di perusahaan dilakukan secara langsung dengan penyusunan berita acara untuk dimasukkan kepada pihak pusat disaat terjadi insiden.

"Sistem pelaporan disini dilakukan dengan cara penanganan langsung, dimana ketika adanya insiden mengenai $\mathrm{K} 3$ tenaga kerja yang bersangkutan langsung dibawa ke Puskebun (Pusat Kesehatan Kebun) milik perusahaan sendiri yang lokasinya memang berada di lokasi PTPN VII, di Puskebun dipastikan tingkat keseriusan kecelakaan dulu, bila tidak perlu dirujuk ke Rumah Sakit langsung ditangani di Puskesbun" (informan 1).

an Sistem Manajemen Kesehatan Dan Keselematan ... 23 sukkan dalam agenda rapat akhir tahun yang mana kami diskusikan dalam rangka menilai efisiensi upaya-upaya K3 di perusahaan" (informan 2).

Tabel 5. SMK 3 Berdasarkan Peninjauan dan peningkatan K3

\begin{tabular}{|c|c|c|}
\hline Kegiatan & Direksi & Tenaga Kerja \\
\hline $\begin{array}{l}\text { Peninjauan dan } \\
\text { peningkatan } \\
\text { Kinerja K3 } \\
\text { Tinjauan awal }\end{array}$ & $\begin{array}{l}\text { Perusahaan da- } \\
\text { lam } \\
\text { melaksanakan } \\
\text { tinjauan awal } \\
\text { pelaksana dari } \\
\text { kantor pusat }\end{array}$ & - \\
\hline $\begin{array}{l}\text { Peningkatan } \\
\text { kinerja K3 }\end{array}$ & \begin{tabular}{l}
\multicolumn{2}{l}{ Peningkatan } \\
kinerja K3 me- \\
lalui promosi \\
jabatan
\end{tabular} & $\begin{array}{l}\text { Tenaga kerja yang } \\
\text { berprestasi dipro- } \\
\text { mosikan kenaikan } \\
\text { jabatan dan tenaga } \\
\text { kerja yang tidak } \\
\text { disiplin dihukum } \\
\text { dengan cara kenai- } \\
\text { akan pangkat di- } \\
\text { tunda. }\end{array}$ \\
\hline
\end{tabular}

Hasil yang ditungkan dalam tabel 5 memberi gambaran bahwa system manajemen K3 melalui peninjauan dan peningkatan K3 semua persyaratan dalam penetapan tersebut sudah dilaksanakan seperti hasil wawancara di berikut ini.

Dalam rangka meningkatkan jaminan kemampuan tenaga kerja berdasarkan hasil wawancara serta kuesioner dan observasi perusahaan sudah melakukan pelatihan untuk meningkatkan skil dan kemampuan kepada semua tenaga kerja secara bertahap dibarengi dengan cara perusahaan melakukan seleksi berdasarkan kriteria-kriteria perusahaan serta sosialisasi dan pengenalan dan prosedurprosedur kerja bagi setiap tenaga kerja khususnya di bidang produksi. Bagi setiap tenaga kerja baru mereka diberi kesempatan untuk melakukan penyesuaian ataupun masa percobaan yang nanti akan berkembang selama tenaga kerja bekerja.

"Kami belum maksimal melakukan upaya peningkatan-peningkatan skill karena setelah menilai kapasitas tenaga kerja berdasarkan riwayat pendidikan memberikan seleksi berdasarkan criteria-kriteria perusahaan serta 
melakukan sosialisasi dan menjelaskan prosedur-prosedur penggunaan mesin, setiap tenaga kerja akan langsung menguasainya sekalipun memang memerlukan penvesuaian 24 Jurnal Media Kesehatan, Volume 8 Nomor 1, April 2015, hlm 01-99 mulai dari tingkat low Manager yaitu tenaga kerja di lapangan sampai tenaga kerja tingkat menengah (Middle Manager) sampai tingkat tinggi (Top Manager) dan penerapan baik saat jukkan bahwa pendokumentasian system Manajemen K3 di PTPN VII belum maksimal ditandai masih dalam jumlah kecil dokumendokumen mengenai pelaksanaan SMK3.

\section{KESIMPULAN}

Sistem Manajemen Kesehatan dan Keselamatan Kerja (SMK3) pada PTPN VII Padang Pelawi telah mengacu pada PP No 50 Tahun 2012. Penerapan pada penetapan kebijakan PTPN VII sebagai salah satu pelaksana saja tidak ikut serta dalam perumusan dan penetapannya dikarenakan kebijakan berasal dari kantor pusat di Lampung. Pada penerapan rencana K3 sudah dilaksanakan namun perencanaan yang terinci belum dilakukan, sedangkan penerapan pelaksanaan rencana K3 PTPN VII sudah melaksanakan secara mandiri dan pelaporan sudah berjenjang dari direksi yang berada pada PTPN VII sampai kantor pusat di Lampung. Penerapan pemantauan dan evaluasi K3 sudah ditunjuk seorang tenaga kerja yang bertanggung jawab dan berwewenang dalam pelaksanaan K3 dan evaluasi dilaksanakan

\section{DAFTAR RUJUKAN}

Anggun.

2011.

(http://psilingkungananggun.blogspot.com/2011/ 02/hubungan-kebisingan-dengan-tingkat.html), diakses 12 Februari 2014 pukul 12.10 WIB.

Dinas Tenaga Kerja, Transmigrasi dan Kependudukan Provinsi Jawa Timur. (http:/dinaskertrasduk.jatimprov.go. id/majalahsdm-plus/64edisi-1).

Habsari, N.D, 2003. Penggunaan Alat Pelindung Diri Bagi Tenaga Kerja, Bunga Rampai Hyperkes dan Keselamatan Kerja. Semarang: UNDIP.

Harrington, JM, \& F.S. Gill. 2003. Buku Saku Kesehatan Kerja. Jakarta: EGC.

Adzim,

Hebbie Ilham. (http:/sistemmanajemenkeselamatankerja.blogsp ot.com/2014/10/pe.)

Moeloeng. 2013. Metodologi Penelitian Kualitatif Edisi Revisi. Bandung: PT Remaja Rosdakarya. pelaksanaan (Proses) dan tinjauan akhir (Out $P u t$ ), untuk penerapan peningkatan $\mathrm{K} 3$ tenaga kerja sudah ada yang mengikuti pelatihan K3.

Pada penerapan Sistem Manajemen Kesehatan dan Keselamatan Kerja (SMK3) diharapkan untuk mendokumentasikan semua kebijakan yang berkaitan dengan SMK3, perencanaan K3 perlu diutamakan terutama yang berkaitan dengan APD. Pelaksanaan K3 perlu dilaksanakan oleh semua tingkatan manajer mulai dari lower manager, middle manager dan top manager. Pada bidang pemantauan dan Evaluasi K3 agar lebih ditingkatkan terutama kepada tenaga kerja (Lower manager) untuk mencegah kecelakaan kerja. Selain itu, peninjauan dan peningkatan K3 perlu untuk mening-katkan pelatihan $\mathrm{K} 3$ bagi tenaga kerja yang berada pada tingkatan lower manager. Bagi tenaga kerja PTPN VII Padang Pelawi hendaknya mematuhi segala prosedur penggunaan APD dan menjaga lingkungan kerja untuk meminimalis terjadinya kecelakaan kerja.

Prabu, Putra. 2008. (http:putraprabu.worddpress.com/2008/12/29/bu nyi \& kebisingan). diakses tanggal 11 Februari 2014 pukul 17.00 WIB.

Ramli, Soehatman. 2010. Pedoman Praktis Manajemen Risiko dalam Perspektif K3 OHS Risk Management. Jakarta: Dian Rakyat.

Ria. 2011. (http://agusria.wordpress.com /2011/03/07/43/). diakses tanggal $11 \quad$ Februari 2014 pukul $17.15 \quad$ WIB.

Ridley, John. 2006. Kesehatan dan Keselamatan Kerja. Jakarta: Erlangga.

Peraturan Pemerintah Republik Indonesia Nomor 50 Tahun 2012. Jakarta.

Subaris. 2008. Hygiene Lingkungan Kerja. Yogyakarta: Mitra Cendekia Press.

Suma'mur. 2009. Hygiene Perusahaan dan Keselamatan Kerja (HIPERKES). CV Sagung Seto.

Pratiknya, WA. 2003. Dasar-dasar Metodologi 
Penelitian Kedokteran dan Kesehatan: cetakan ke V. Jakarta: PT Raja Grafindo Persada. Subagyo, (http://consultantiso.blogspot.com/2013/07/imple mentasi-sistem-man).

Wardhana, Wisnu Arya. 2004. Dampak Pencemaran Lingkungan. Yogyakarta: Andi Yogyakarta. 